Original Research Paper

\title{
An Exploratory Analysis to Assess Computer Literacy and E- learning Among Students: A Case of Eastern Province of Kingdom of Saudi Arabia
}

\author{
${ }^{1}$ Manal Elobaid and ${ }^{2}$ Rafida M. Elobaid \\ ${ }^{1}$ Cor Curriculum Program - Qatar Uuniversity, Doha, Qatar \\ ${ }^{2}$ Department of General Sciences, Women College, Prince Sultan University, Riyadh, KSA
}

\author{
Article history \\ Received: 04-04-2017 \\ Revised: 02-07-2017 \\ Accepted: 20-07-2017 \\ Corresponding Author: \\ Rafida M. Elobaid \\ Department of General \\ Sciences, Women College, \\ Prince Sultan University, \\ Riyadh, KSA \\ Email: robaid@psu.edu.sa
}

\begin{abstract}
The current study investigated the use of ICT within the schools and higher education sectors in the eastern province of kingdom of Saudi Arabia. The objective is to evaluate how computer literacy and the implementation of e-learning could contribute to the learning and teaching process within the education sector in this area. A cross sectional survey was carried out among students. A website was designed to gather the data through questionnaire and interview. The data was analyzed with routine statistical tools. The results show that the students favorite place to get access to a computer is their home. High percentages of students were capable of working with windows functions and affirmed that computer programs and models helping a great deal in understanding the courses. The study revealed that secondary schools students were hardly using e-learning technologies compared with higher education sector. The research implied fairly good mastery of ICT and student interest in following the development in computer education which opens new outlook to the education sector in this area. However, effective measures to promote the usage of e-learning facilities should be provided and more efforts should be made to improve e-learning facilities in schools.
\end{abstract}

Keywords: Information and Communication Technologies (ICT), Elearning, Computer Literacy, Windows Literacy, Computer Educational Models, Chi- Square Test

\section{Introduction}

Computer literacy forms the basis for lifelong learning (Lant, 2001). The developments in ICT lead to the idea of computer literacy. The level of computer literacy one must attain depends on the society and the position of the individual in the society's hierarchy.

To establish a computer literate society, special attention should be given to the students. Knox and Schmidt (2006) suggest fostering the importance of scientific literacy in students early and reinforcing it throughout life.

Saudi higher education has seen massive investment in recent years (Krieger, 2007). It has faced great challenges in academic teaching and witnessed a rapid revolution in the use of ICT and e-learning standards. To ensure the best possible employment of ICT at all levels in education and training and the use of e-learning, the
Saudi government produced the National Communications and Information Technology plan (NCITP) in 2007 (MCIT, 2007). It was established by Ministry of Higher Education (MoHE) to encourage and support e-learning in higher education (Alebaikan, 2010). To support the development of e-learning in Saudi higher education, MoHE set up the National Centre for E-learning and Distance Learning (NCeL) with the assistance of the Open University of Malaysia (OUM) and Multimedia Technology Enhancement Operations (MTEO) in 2006 (Almohaisen, 2007). It also supported university course materials by establishing a Learning Management System (LMS) called 'JUSUR' in 2007 (Alebaikan and Troudi, 2010, Al-Khalifa, 2010; Mirza, 2007). The Saudi Center for support and counseling (SANEED) was set up by NCeL to support, guide and improve the abilities of all e-learning users in Saudi universities. 
However, although the use of ICT has been adopted and encouraged by the Ministry of Higher Education with e-learning to meet that demand in kingdom of Saudi Arabia (Alebaikan, 2010; Aljabre, 2012), there still is a lack of evidence of students adopting computer literacy in the eastern province of the kingdom. This might be due to fact that ICT and e-learning is still under development (Al-Khalifa, 2009).

This paper evaluates the computer literacy of the students of schools and higher education sectors within the eastern province of Saudi Arabia and their implementation of e-learning in order to enhance the quality of learning and teaching.

\section{Methodology}

A cross-sectional study based on a questionnaire and one to one interview based survey was conducted. The study comprised of students in both universities and secondary school in the eastern province of KSA. A questionnaire developed by the Research Deanship of King Faisal University was applied. A website (www.kfuresearch.info) was designed by the research team and launched for one year with the administrative agreement of Research Deanship of King Faisal University. By the end of the year the website was closed to input the data and to start the analysis. The website contained all the detailed information about the research goals, researchers contact information and survey links for user-friendly access. Pamphlets were graphically designed with easy to follow instructions directing to access the survey links in the website. An email including the research introduction, a link to the website and the survey, was broadcasted to all the students. The research team met members of selected schools who accepted to participate and relied on them in order to sensitize students their voluntary participation. Soft copies were sent through emails and 200 hard copies were distributed in these schools. A one to one interview was also conducted among a number of students and the questionnaires were then collected directly after being completed during an appointment with a member of the research team.

A sample size of 1765 students was selected at random, out of which 95 students were asked to accomplish the survey manually. Excluding the general questions, the questionnaire was designed with 24 questions. This research paper investigated the following;

\section{Computer Access}

Questions about where and how often student uses the computer were asked.

\section{Level of Windows Literacy}

The questions were designed in this part to investigate the students training and skills in windows and software. The students were also asked about their ability to work with different tasks in windows such as desktop, antivirus and control panel. Questions about their ability to install and remove different types of software were also designed.

\section{Usefulness of Computer Educational Models}

This part of the survey includes questions about if the computer programs and models are useful in helping students to understand course concepts and if the teachers should make greater use of computers and computer models in the class.

\section{Usage of E-learning Technology}

The students were asked about which type of Elearning Technology tools they use to help them in study. They were also asked about the frequency of using these tools in study and in communicating with the instructors. Various methods of questioning were proposed such as cross tabulation, multiple choices, Likert's scale type questions and mix of open and closed ended questions.

Statistical procedures were used and Chi-square test was conducted using the following formula:

$$
x_{i j}^{2}=\sum_{i=1}^{r} \sum_{j=1}^{c} \frac{\left(e_{i j}-o_{i j}\right)^{2}}{e_{i j}}
$$

Chi-sq test was used to examine the relationship between type of organization and the usefulness of computer models in the class as well as the e-learning technology usage. A significant level of 0.05 was assigned and compared with p-value to make the decision.

The data was collected and designed through the online survey site; Survey Monkey. The site was selected by the research team after comparing it with the top 10 survey creating software. The data was then analyzed with the statistical software SPSS 17.0. All participants were fully informed about the objectives of this study and agreed to voluntarily participate.

\section{Results}

\section{Response Rates}

One thousand seven hundred sixty five (1765) questionnaires were completed and analyzed: 292 $(16.5 \%)$ from the school's students, 1432 (81.3\%) from the universities (preparatory year, bachelor and post graduate) students and $41(2.3 \%)$ from the diploma students which classified in category 'others'. Table 1 and Fig. 1 display the number of responses for each category. 


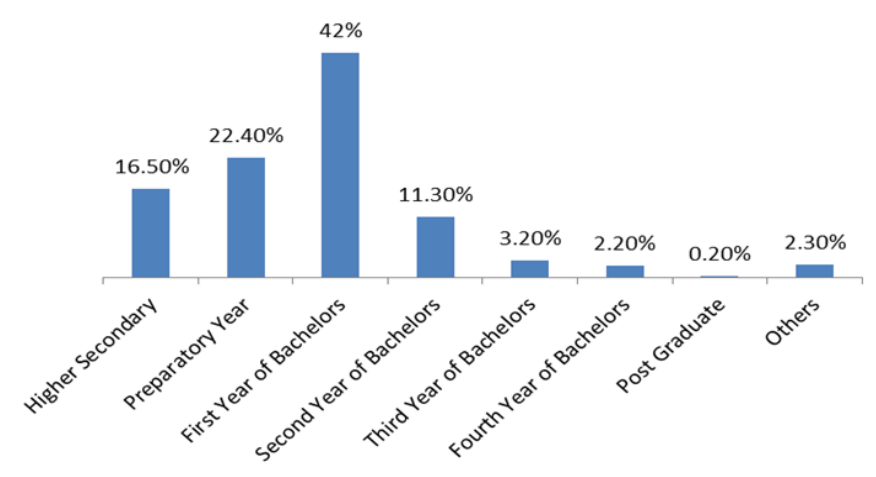

Fig. 1. Student survey responses

Table 1. Student survey responses

\begin{tabular}{lcr}
\hline Degree & Response percent & Response count \\
\hline Higher Secondary & 16.5 & 292 \\
Preparatory Year & 22.4 & 395 \\
First Year of Bachelors & 42.0 & 741 \\
Second Year of Bachelors & 11.3 & 199 \\
Third Year of Bachelors & 3.2 & 56 \\
Fourth Year of Bachelors & 2.2 & 38 \\
Post Graduate & 0.2 & 3 \\
Others & 2.3 & 41 \\
Total & 1765.0 & \\
\hline
\end{tabular}

Table 2. Student computer access

\begin{tabular}{lcc}
\hline Computer access & Responses & Percent \\
\hline At school/college & 269 & 17 \\
At home & 1201 & 76 \\
At net cafe & 110 & 7 \\
Total & 1580 & 100 \\
\hline
\end{tabular}

\section{Computer Access}

The frequency for students who use computer at school/college, home and net cafe was obtained. Out of 1765 , the total number of responses was 1580 . The results show that the majority of students $(76 \%)$ use computer at home as reported in Table 2 and Fig. 2.

\section{Level of Windows Literacy}

Multiple response questions were designed to scrutinize students' computer skills and evaluate their background in windows operating systems and windows literacy in software. The results show that $1.2 \%$ of the students had very poor computer skills while $55 \%$ of them had very good computer skills.

The results in Table 3 and 4 reported the students' background in windows operating systems and windows literacy in software respectively. The total number of students who responded to each of these two categories was 1564 . The majority of participants in the study have background in windows operating system and windows software. However, it is important to underline that $2.9 \%$ of students still can't work with windows operating system and $6.4 \%$ of students can't install any software. Figure 3 displays the results for windows operating system and windows literacy in software. a Student use computer at school/college

\section{Student use computer at home \\ in Student use computer at net café}

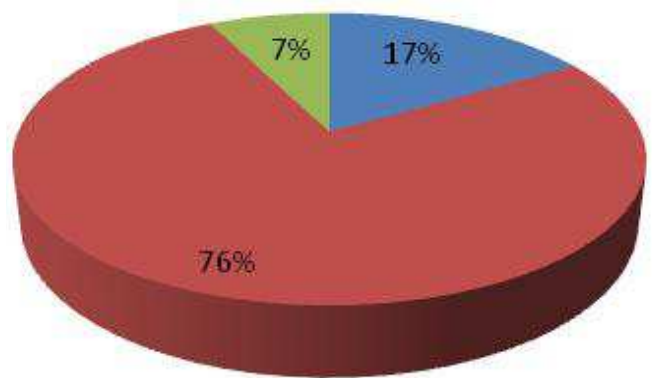

Fig. 2. Student computer access

\section{Computer Educational Models}

Students perception of the usefulness of computer programs and models in understanding the course concepts was evaluated. Table 5 displays the responses of 1559 participants of schools and higher education sectors. Though computer programs and models are not frequently used in the eastern province schools, students in both sectors show high percentages towards them helping a great deal in understanding the courses. Using Chi-sq test statistics the $\mathrm{p}$ value was 0.0015 indicating that there is significant relationship between the types of organization and the usefulness of computer models in the class at significant level of 0.05 . 


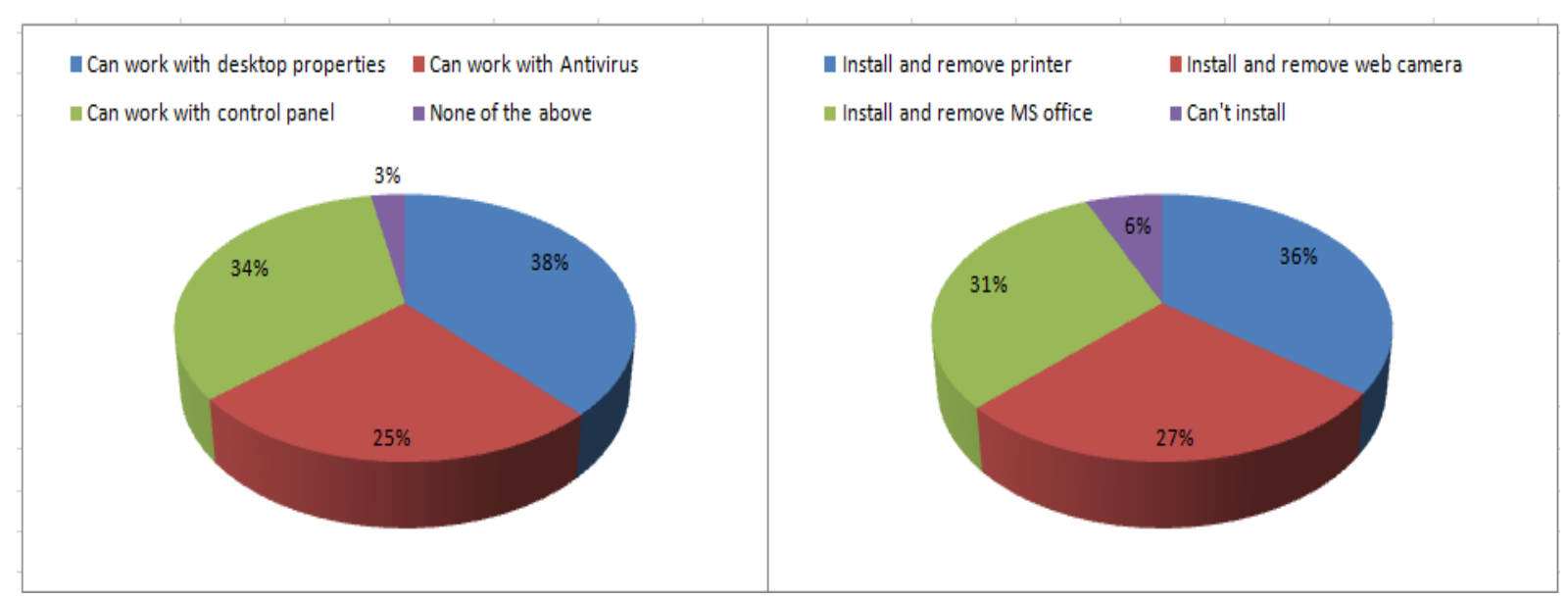

Fig. 3. Level of Windows literacy in windows operating system and software

Table 3. Level of Windows literacy in windows operating system

\begin{tabular}{lccr}
\hline Windows operating system & Count & Responses (\%) & Cases (\%) \\
\hline Can work with desktop properties & 1357 & 38.3 & 86.8 \\
Can work with Antivirus & 895 & 25.3 & 57.2 \\
Can work with control panel & 1187 & 33.5 & 75.9 \\
None of the above & 101 & 2.9 & 6.0 \\
Total responses & 3540 & 100.0 & 226.3 \\
\hline
\end{tabular}

Table 4. Level of Windows literacy in software

\begin{tabular}{lccc} 
Type of software & Count & Responses (\%) & Cases (\%) \\
\hline Install and remove printer & 1197 & 35.6 & 76.75 \\
Install and remove web camera & 904 & 26.9 & 57.90 \\
Install and remove MS office & 1042 & 31.0 & 66.80 \\
Can't install & 216 & 6.4 & 13.80 \\
Total responses & 3359 & 100.0 & 215.20 \\
\hline
\end{tabular}

Table 5. Usefulness of computer models in the class

\begin{tabular}{llrrr} 
& Teachers should make greater use of computers and models in the class & Total \\
Organization & & Yes & No & 268.0 \\
\hline Schools & Count & 235.0 & 33.0 & 100.0 \\
& $\%$ & 87.7 & 12.3 & 1291.0 \\
Higher Educ. & Count & 1205.0 & 86.0 & 100.0 \\
& $\%$ & 93.3 & 6.7 & 1559.0 \\
Total & Count & 1440.0 & 7.0 & 100.0 \\
& $\%$ & 92.4 & 7.6 & \\
\hline
\end{tabular}

Table 6. Usage of e-learning programs

\begin{tabular}{|c|c|c|c|c|c|c|}
\hline \multirow[b]{2}{*}{ Type of organization } & & \multicolumn{4}{|c|}{ Usage of E-learning technology tools per semester } & \multirow[b]{2}{*}{ Total } \\
\hline & & Never & Rarely & Some times & Always & \\
\hline \multirow{2}{*}{ Schools } & Count & 17.0 & 15.0 & 27.0 & 20.0 & 79.0 \\
\hline & $\%$ & 21.5 & 19.0 & 34.2 & 25.3 & 100.0 \\
\hline \multirow[t]{2}{*}{ Higher Educ. } & Count & 91.0 & 181.0 & 371.0 & 651.0 & 1294.0 \\
\hline & $\%$ & 7.0 & 14.0 & 28.7 & 50.3 & 100.0 \\
\hline
\end{tabular}

\section{Usage of E-learning Technology}

The results show that e-learning tools remain mostly unused to school students. Only $25.3 \%$ of students have always used it per semester. In higher education sector $50.3 \%$ of students have used elearning technology while $7 \%$ never used it as shown in Table 6, the later percentage should be highlighted. Chi-sq test statistics was significant at 0.05 and 0.001 levels indicating that there is a 
relationship between the type of organization and the E-learning technology usage.

\section{Discussion}

This is the first study focusing on the student use of ICT in the education sector of the eastern province of KSA. The rapid diffusion of ICT throughout the world recommended, at a large scale, the incorporation of ICT within high school and university levels even though the majority of the students in this study reported that their favorite place to get access to a computer is their home. A study conducted by Bediang et al. (2013) explained this by the fact that the participants consider the educational institution as a place of knowledge acquisition, the understanding and assimilating steps of this knowledge takes place in a more intimate and familiar environment. The insufficient quality of services related to the computers access and other services like documents printing or photocopying at schools or campus, may explain some dissatisfaction as reported in some studies (Piccoli and Ives, 2001; Webster and Hackley, 1997).

Students knowledge on Windows operating system and software denotes that few percentages of them are incapable of working with functions such as desktop properties, antivirus, control panel and installations and large percentages can handle Windows appropriately with thorough knowledge.

Moreover, participants in this study show high percentages towards computer programs and models helping a great deal in understanding the courses. The test statistics used confirms this result and show significant relationship between the types of organizations and the usefulness of computer models in the class.

When asked about the implementation of e-learning, the survey reported a high percentage of secondary schools participants that never use any e-learning technologies. This can be attributed to the fact that public access to the internet in Saudi Arabia was allowed in 1997 followed by a slow start to the adoption of internet as pointed out by Sait et al. (2003). Aldraiby (2010) reported that the implementation of e-learning in Saudi Arabia faces various barriers, which mainly arise from the educational society of Saudi Arabia.

In higher education sector the percentages of students that never implemented e-learning tools to aid their teaching is still a significant figure, though this percentage is small compared to those who state that they always use it. Here we would like to specify that there should be effective measures to promote the usage of e-learning facilities in order to get acquainted with the e-services. However, it is important to mention that the government of Saudi Arabia is currently expanding its education systems though budgetary allocations.
Moreover, different studies show that most students are of the view that inclusion of technological tools into education is one mode of achieving development in education (Alebaikan, 2012). The study also shows that the implementation of e-learning tools is influenced by the type of educational organization whether it is the school or higher educational institution.

\section{Conclusion}

The contribution of the current study is to give an idea about computer literacy at the schools and higher education sectors in the eastern province of kingdom of Saudi Arabia. A fairly good mastery of ICT and student interest in following the development in computer education which opens new outlook to the education sector in this area was observed. The huge potential offered by the government of Saudi Arabia in improving implementation of e-learning in teaching and learning still remains largely unexploited in particular at schools sector. However, students are convinced of ICT and e-learning utility and applicability. This opens new perspectives to find and adopt more effective tools to improve implementation of e-leaning in teaching and learning. Students interest in using ICT will reveal by utilizing concrete measures to enhance and improve the quality of services related to the computers access and other services at schools.

\section{Funding Information}

The authors acknowledge Research Deanship of King Faisal University for providing the financial support through project.DSR Project (No.: 110121).

\section{Author's Contributions}

Manal Elobaid: Design the research plan, data collection, contribute to the writing of manuscript.

Rafida M. Elobaid: Data analysis and writing the manuscript.

\section{Ethics}

This article is original and contains unpublished material. Participants are made known that their feedbacks will be contributing to a research project. The corresponding author confirms that all of the other authors have read and approved the manuscript and no ethical issues involved.

\section{References}

Aldraiby, O., 2010. E-Learning and its effectiveness in Saudi Arabia. 
Alebaikan, R., 2010. Perceptions of blended learning in Saudi Universities. PhD Thesis, University of Exeter.

Alebaikan, R., 2012. The future of blended learning. Proceedings of the World Academy of Science, Engineering and Technology, (SET' 12), pp: 484-488.

Alebaikan, R. and S. Troudi, 2010. Online discussion in blended courses at Saudi Universities. Proc. Soc. Behav. Sci., 2: 507-514. DOI: $10.1016 /$ j.sbspro.2010.03.054.

Aljabre, A., 2012. An exploration of distance learning in Saudi Arabian universities: Current practices and future possibilities. Int. J. Bus. Human. Technol., 9: 21-28.

Almohaisen, I., 2007. E-learning in the Kingdom of Saudi Arabia. National Centre for Distance and ELearning Seminar, Keynote speech, Riyadh.

Al-Khalifa, H.S., 2009. The state of distance education in Saudi Arabia. E-Learn Magazine.

Al-Khalifa, H.S., 2010. A first step in evaluating the usability of JUSUR learning management system. Proceedings of the 3nd Annual Forum on eLearning Excellence in the Middle East, (EME' 10), Dubai, UAE.

Bediang, G., B. Stoll, A. Geissbuhler, A.M. Stuckelberger and A., Nko'o et al., 2013. Computer literacy and elearning perception in Cameroon: The case of Yaounde Faculty of Medicine and Biomedical Sciences. BMC Med. Educ., 13: 57-57.

DOI: $10.1186 / 1472-6920-13-57$.
Knox, K. and B. Schmidt, 2006. A wake-up call on science literacy, Canada's future depends on it. Policy Opt., 27: 74-77.

Krieger, Z., 2007. Saudi Arabia Puts Its Billions Behind Western Style Higher Education. The Chronicle of Higher Education.

Lant, K.M., 2001. Information literacy and teaching with technology. Illinois, University of Illinois.

MCIT, 2007. The national communications and information technology plan: The vision toward the information society, Saudi Arabia. Ministry of Communications and Information Technology.

Mirza, A., 2007. Is e-learning finally gaining legitimacy in Saudi Arabia? Saudi Comput. J., 6: 74-79.

Piccoli, G., R. Ahmad and B. Ives, 2001. Web-based virtual learning environments: A research framework and a preliminary assessment of effectiveness in basic IT skills training. MIS Q., 25: 401-426. DOI: 10.2307/3250989.

Sait, S., S. Ali and K. Al-Tawil, 2003. Perceptions about e-learning in Saudi Arabia. Proceedings of the International Council of Associations for Science Education, (ASE' 03), Penang, Malaysia.

Webster, J. and P. Hackley, 1997. Teaching effectiveness in technology-mediated distance learning. Acad. Manage. J., 40: 1282-1309. DOI: $10.2307 / 257034$. 